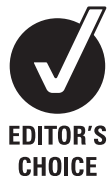

CHOICE

\title{
Social inequalities in health among adolescents in a large southern European city
}

\author{
T Duarte-Salles, ${ }^{1}$ M I Pasarín, ${ }^{1,2,3}$ C Borrell, ${ }^{1,2,3}$ M Rodríguez-Sanz, ${ }^{1,2,3}$ L Rajmil, ${ }^{3,4}$ \\ M Ferrer, ${ }^{3,4}$ F Pellisé, $^{5} \mathrm{~F}$ Balagué ${ }^{6}$
}

${ }^{1}$ Universidad Pompeu Fabra, Barcelona, Spain

${ }^{2}$ Agència de Salut Pública de Barcelona (ASPB), Barcelona, Spain

${ }^{3}$ CIBER Epidemiología y Salud Pública (CIBERESP), Spain

${ }^{4}$ Agència d'Avaluació de Tecnología i Recerca Mèdiques (AATRM), Barcelona, Spain ${ }^{5}$ Hospital Universitari de la Vall d'Hebrón, Barcelona, Spain ${ }^{6}$ Hôpital Cantonal, Fribourg, Switzerland

\section{Correspondence to}

Talita Duarte Salles, Centro de Investigación en Epidemiología Ambiental, Dr Aiguader 88, Barcelona 08003, Spain; tduarte@creal.cat

Accepted 19 November 2009 Published Online First

8 December 2009

\begin{abstract}
Background Numerous health problems are initiated in childhood and adolescence. For example, obesity, which has increased significantly in recent years, often begins in early life. The objective of this study is to describe social inequalities in obesity and other health problems among adolescents, by sex.
\end{abstract}

Methods Data were from a cross-sectional study conducted in a representative sample of 903 adolescents aged 12-16 years old, from secondary schools in Barcelona, Spain. Associations between socioeconomic indicators and health outcomes (perceived health status, and overweight and obesity) were examined through generalised estimating equation models. All analyses were stratified by sex.

Results Boys were more likely to report very good perceived health status than girls $164.1 \%$ and $46.3 \%$, respectively). Some of the less privileged socioeconomic position indicators were associated with the presence of overweight and obesity (prevalence ratio 2.41 for low family affluence scale in girls), and with a lower probability of reporting very good perceived health status among boys (prevalence ratio 0.75 for primary level of paternal education).

Conclusions This study suggests that there are social inequalities in perceived health status, overweight and obesity, measured by different socioeconomic indicators among the adolescent population of Barcelona, and that these inequalities were distributed differently among boys and girls. Gender differences in the impact of socioeconomic variables in health need to be considered in epidemiological and intervention studies.

Inequalities in access to resources and health status among human beings from the same community or different geographic areas have been found and discussed for centuries, ${ }^{1}$ and continue to be subject of debate as they constitute a reality that is constantly growing in our society. ${ }^{2}$

Adolescence is a transitional period characterised by growth and biological, physiological, psychological and social maturation. Although the study of social inequalities in health has been extensively expanded since the publication of the Black Report, ${ }^{3}$ it has not been so exhaustively analysed in the adolescent population. The recent publication of a report into inequalities in young people's health by Currie et $a l^{4}$ has generated a growth of interest in the effects of socioeconomic status on adolescent's health. However, there are still relatively few countries that have prioritised health in these groups, due to its low mortality and morbidity associated to natural causes of disease. ${ }^{5}$
While some studies have found either weak or no association between socioeconomic status and health of young people, ${ }^{6}$ others have found a strong association. In this regard, Due et al reported a relationship between parents' socioeconomic position, and physical and psychological symptoms in boys and girls aged 11, 13 and 15 years.

On the other hand, adolescence has a vital importance in many aspects, such as the adoption of healthy or risky lifestyles, which may determine the individual's health in adult life. ${ }^{89}$ Some health problems that are initiated in childhood and adolescence are becoming more common. Obesity, for instance, has become an epidemic worldwide, ${ }^{10}$ and WHO has recently declared obesity as one of the greatest public health challenges for the 21st century as it is associated with the presence of risk factors for the development of later diseases. ${ }^{11}$ In industrialised countries, several studies show an inverse relationship between socioeconomic status and overweight or obesity in adults. ${ }^{12}{ }^{13}$ In adolescents and children, however, such relationships are inconsistent, and few studies have analysed the effect of socioeconomic status on overweight and obesity. While some studies show an inverse relationship between socioeconomic status and overweight or obesity in adolescents, ${ }^{14-16}$ no association was observed in other studies. $^{12} 1718$ One of the explanations for such differences in study findings has been the use of different measures of socioeconomic status. ${ }^{4}$ For this reason, different measures of socioeconomic status are used in the present study to identify social inequalities. Moreover, it is possible that each socioeconomic indicator have a different effect on adolescent's health.

Due to the low morbidity and mortality among adolescents, another key health indicator to identify social inequalities in this population is perceived health status. This is a subjective indicator of general health that that has been found to be predictive of objective health outcomes in adults. ${ }^{19} 20$ Recently, a report showed that low family affluence was significantly associated with higher levels of fair or poor health in many European countries. ${ }^{4}$

As these health problems have long-term implications for health, ${ }^{89}$ they could probably be related with health inequalities in later life. For this reason, a better knowledge of the determinants of health in young population is essential for setting up adapted programs.

The objective of this study is to describe social inequalities in health indicators (perceived health status (PHS) and overweight and obesity) among 
adolescents, aged from 12 to 16 years, in the city of Barcelona, by sex.

\section{METHODS}

\section{Design and study sample}

Data were from a cross-sectional study ${ }^{21}$ conducted in secondary schools of Barcelona, Spain, between April and June 2006. Barcelona is located in the north-eastern coast and had a population of 1605602 in 2006. A representative sample of adolescents aged 12-16 years, from public and private or subsidised secondary schools (grades 1-4), was selected using two-stage cluster sampling. The schools were stratified by type of school (public-private) and by the family economic capacity index $(\mathrm{ICEF})^{22}$ (high, medium and low, in tertiles). The ICEF is used as an indicator of the socioeconomic level of the school, taking into account the neighbourhood in which it is located. In the first stage, a random sample of schools stratified by type of school and ICEF was selected, and in the second stage classrooms were taken as the sampling unit. Finally, all adolescents in each classroom selected were included. Sample size was calculated as 900 adolescents assuming a low back pain prevalence of $15 \%$ and a response rate of $75 \%$, with an $\alpha$ risk of $5 \%$ and a statistical power of $80 \%$.

After approval by the ethics committee of the Vall d'Hebrón Hospital, 20 school administrators were contacted. All adolescents who participated in the study self-completed the questionnaire during class time, under the supervision of school nurses from the Barcelona Public Health Agency.

The questionnaire included sociodemographic variables and questions about general health status.

\section{Health indicators}

To measure PHS, subjects were asked whether their health was, in general, poor, fair, good, very good or excellent. Responses were subsequently recoded into three categories: "very good" (very good or excellent health), "good" (good) and "poor" (fair or poor).

Body mass index (BMI) was calculated for each individual based on self-reported weight and height. Overweight and obesity were classified based on the BMI percentiles charts, specific for age and sex, using the charts of the Orbegozo Foundation ${ }^{23}$ developed for the Spanish population. "Obesity" was defined as BMI $\geq 95$ th percentile, "overweight" as BMI $\geq 85$ th to $<95$ th percentile. ${ }^{24}$

\section{Socioeconomic and sociodemographic indicators}

Sociodemographic characteristics analysed were sex, age and type of school (private/subsidized and public).

Social class was determined using an open question about the current or last occupation of parents and coded according to the National Spanish Classification of Occupations. Social class of parents was classified into five groups (I-V) according to the Spanish Society of Epidemiology. ${ }^{25}$ Class I includes managers and senior technical staff and freelance professionals; class II, intermediate occupations and managers in commerce; class III, skilled non-manual workers; class IV, skilled (IVa) and partly skilled (IVb) manual workers; and class $\mathrm{V}$, unskilled manual workers. These were then collapsed into two categories: nonmanuals (classes I-III) and manuals (classes IV-V). After that, the highest social class category of both parents were used to create the variable of family's social class, which helped to decrease the number of missing data because the social class of the head of the household was assigned when occupation of one of the parents was not reported.
Subjects were also asked about the highest level of education of both parents, which was grouped in the following strata: primary school or less (under 9 years of schooling), secondary education (10-14 years) and university qualifications (15 years or more).

The family affluence scale (FAS) is a socioeconomic indicator designed to be answered by children and adolescents, which includes information about family car ownership, bedroom occupancy, family holidays in the past 12 months and computer ownership. A composite score was calculated for each subject based on the sum of responses of these four items producing an ordinal scale from 0 to 7 , which was recoded into three categories: low (0-3), intermediate (4-5) and high affluence (6-7) levels. $^{26}$

Family structure and chronic diseases or disabilities were used as control variables. Family structure was obtained based on the number of people living in the household and their relationship with the subject and then categorised into three groups: "two-parent family", if the subject lived with both parents; "mixed", living with one parent and other adults; and "single parent or other", living with only one parent or other adults. Prevalence of chronic disease was obtained through a single question: "Do you have any disability, illness or chronic medical problem?" (yes or no).

\section{Data analysis}

All analyses were carried out separately by sex, as it is already known that incidence or determinant factors of the dependent variables are differently distributed among boys and girls. ${ }^{27}$ First, a descriptive analysis was carried out by calculating the prevalence of health indicators between independent variables. Differences between sex groups were assessed using $\chi^{2}$ tests of significance. To study the relationship between health and socioeconomic position indicators, bivariate analyses were performed by calculating unadjusted prevalence ratios (PR) and their $95 \%$ CIs. ${ }^{28}$ Multivariate analyses were conducted through generalised estimating equation models to account for the clustering of respondents within school, adjusting for possible confounding variables (age, family structure and chronic condition in the case of PHS). Independent models were constructed for the different socioeconomic indicators in the multivariate analysis of social inequalities. A difference was considered to be statistically significant when the $p$ value is $<0.05$. Data were analysed using SPSS 16.0 and STATA 10.

\section{RESULTS}

\section{Characteristics of the sample}

The total number of adolescents in the selected classrooms was 1079. On the day of the study, 176 subjects were absent from school or refused to complete the questionnaire. Ultimately, a total of 903 subjects, $52 \%$ boys and $48 \%$ girls, completed the questionnaire. Table 1 describes the distribution of the characteristics of the sample by sex. The proportions of subjects reporting having chronic condition were $14.3 \%$ in boys and $11.3 \%$ in girls; $57.5 \%$ lived in a two-parent family, and $39.9 \%$ belonged to the most privileged level of family affluence scale. Some variables of the study presented nearly $20 \%$ of nonresponse among boys and girls (BMI 16.4\% and 19.6\%; level of paternal education $20.4 \%$ and $18.9 \%$, respectively).

\section{Perceived health status}

Boys were more likely to report very good PHS than girls. While the percentage of adolescents having poor PHS was similar 
Table 1 Sociodemographic and health indicators (number of cases (n) and percentages (\%)), and missing responses in a sample of adolescents in Barcelona

\begin{tabular}{|c|c|c|c|c|c|c|c|c|}
\hline & \multicolumn{4}{|c|}{ Boys $(52 \%)$} & \multicolumn{3}{|c|}{ Girls $(48 \%)$} & \multirow[b]{2}{*}{$\begin{array}{l}\text { Missing } \\
\text { responses \% }\end{array}$} \\
\hline & $\mathbf{n}$ & $\%$ & $\begin{array}{l}\text { Missing } \\
\text { responses n }\end{array}$ & $\begin{array}{l}\text { Missing } \\
\text { responses \% }\end{array}$ & $\mathbf{n}$ & $\%$ & $\begin{array}{l}\text { Missing } \\
\text { responses n }\end{array}$ & \\
\hline \multicolumn{9}{|l|}{ Dependent variables } \\
\hline BMI & & & 77 & 16.4 & & & 85 & 19.6 \\
\hline Low weight & 9 & 2.3 & & & 8 & 2.3 & & \\
\hline Normal weight & 340 & 86.5 & & & 297 & 85.3 & & \\
\hline Overweight & 29 & 7.4 & & & 20 & 5.8 & & \\
\hline Obesity & 15 & 3.8 & & & 23 & 6.6 & & \\
\hline Total & 393 & 100 & & & 348 & 100 & & \\
\hline Self-reported health* & & & 7 & 1.5 & & & 5 & 1.2 \\
\hline Very good & 297 & 64.1 & & & 198 & 46.3 & & \\
\hline Good & 135 & 29.2 & & & 197 & 46 & & \\
\hline Poor & 31 & 6.7 & & & 33 & 7.7 & & \\
\hline Total & 463 & 100 & & & 428 & 100 & & \\
\hline \multicolumn{9}{|l|}{ Independent variables } \\
\hline Age, years & & & 18 & 3.8 & & & 13 & 3 \\
\hline $12-13$ & 145 & 32.1 & & & 158 & 37.6 & & \\
\hline 14 & 121 & 26.8 & & & 95 & 22.6 & & \\
\hline $15-16$ & 186 & 41.1 & & & 167 & 39.8 & & \\
\hline Total & 452 & 100 & & & 420 & 100 & & \\
\hline Type of school & & & 0 & 0 & & & 0 & 0 \\
\hline Private/subsidized & 335 & 71.3 & & & 306 & 70.7 & & \\
\hline Public & 135 & 28.7 & & & 127 & 29.3 & & \\
\hline Total & 470 & 100 & & & 433 & 100 & & \\
\hline Level of paternal education & & & 96 & 20.4 & & & 82 & 18.9 \\
\hline University & 207 & 55.4 & & & 182 & 51.9 & & \\
\hline Secondary & 122 & 32.6 & & & 117 & 33.3 & & \\
\hline Primary & 45 & 12 & & & 52 & 14.8 & & \\
\hline Total & 374 & 100 & & & 351 & 100 & & \\
\hline Level of maternal education & & & 98 & 20.9 & & & 71 & 16.4 \\
\hline University & 204 & 54.8 & & & 171 & 47.2 & & \\
\hline Secondary & 123 & 33.1 & & & 147 & 40.6 & & \\
\hline Primary & 45 & 12.1 & & & 44 & 12.2 & & \\
\hline Total & 372 & 100 & & & 362 & 100 & & \\
\hline Family's social class & & & 39 & 8.3 & & & 20 & 4.6 \\
\hline Non-manuals & 305 & 70.8 & & & 293 & 71.0 & & \\
\hline Manuals & 126 & 29.2 & & & 120 & 29.0 & & \\
\hline Total & 431 & 100 & & & 413 & 100 & & \\
\hline FAS & & & 19 & 4 & & & 8 & 1.8 \\
\hline High & 200 & 44.3 & & & 161 & 37.9 & & \\
\hline Middle & 186 & 41.3 & & & 194 & 45.6 & & \\
\hline Low & 65 & 14.4 & & & 70 & 16.5 & & \\
\hline Total & 451 & 100 & & & 425 & 100 & & \\
\hline Family structure & & & 0 & 0 & & & 2 & 0.5 \\
\hline Two-parent family & 271 & 57.6 & & & 249 & 57.8 & & \\
\hline Mixed & 147 & 31.3 & & & 129 & 29.9 & & \\
\hline Single parent or other & 52 & 11.1 & & & 53 & 12.3 & & \\
\hline Total & 470 & 100 & & & 431 & 100 & & \\
\hline Chronic condition & & & 7 & 1.5 & & & 7 & 1.6 \\
\hline No & 397 & 85.7 & & & 378 & 88.7 & & \\
\hline Yes & 66 & 14.3 & & & 48 & 11.3 & & \\
\hline Total & 463 & 100 & & & 426 & 100 & & \\
\hline
\end{tabular}

between boys and girls (6.7\% and $7.7 \%$, respectively), differences for those having very good PHS $(64.1 \%$ and $46.3 \%)$ were statistically significant (table 1 ).

Table 2 shows the results of bivariate binomial regression models for PHS according to socioeconomic position and confounding variables. The probability of reporting a very good PHS decreased with age. Although this gradient was found in boys and girls, the association was only statistically significant among girls aged $15-16$ years (PR $0.74 ; 95 \%$ CI 0.59 to 0.94 ). Among girls, the presence of any chronic condition (PR 0.55; $95 \%$ CI 0.34 to 0.89 ) was also associated with a lower probability of having a very good PHS, whereas, in boys, this association was of borderline significance (PR 0.68; 95\% CI 0.61 to 1.00 ). In addition, girls living in families classified as single parent or other were less 
Table 2 Very good perceived health status among boys and girls of Barcelona, 2006

\begin{tabular}{|c|c|c|c|c|c|c|}
\hline & \multicolumn{6}{|c|}{ Very good perceived health } \\
\hline & \multicolumn{3}{|l|}{ Boys } & \multicolumn{3}{|l|}{ Girls } \\
\hline & Prevalence (\%) & PR & $95 \% \mathrm{CI}$ & Prevalence (\%) & PR & $95 \% \mathrm{CI}$ \\
\hline \multicolumn{7}{|l|}{ Age, years } \\
\hline $12-13$ & 69.4 & 1 & & 53.8 & 1 & \\
\hline 14 & 63.0 & 0.90 & 0.76 to 1.08 & 45.7 & 0.84 & 0.65 to 1.10 \\
\hline $15-16$ & 59.9 & 0.86 & 0.73 to 1.01 & 40.4 & 0.74 & 0.59 to 0.94 \\
\hline \multicolumn{7}{|l|}{ Type of school } \\
\hline Private/subsidized & 63.7 & 1 & & 48.2 & 1 & \\
\hline Public & 65.2 & 1.02 & 0.88 to 1.18 & 41.6 & 0.86 & 0.68 to 1.09 \\
\hline \multicolumn{7}{|l|}{ Level of paternal education } \\
\hline University & 71.4 & 1 & & 50.6 & 1 & \\
\hline Secondary & 64.2 & 0.89 & 0.76 to 1.05 & 45.3 & 0.89 & 0.70 to 1.14 \\
\hline Primary & 51.1 & 0.71 & 0.53 to 0.96 & 37.3 & 0.73 & 0.50 to 1.08 \\
\hline Missing responses & 54.7 & 0.76 & 0.62 to 0.93 & 43.8 & 0.86 & 0.64 to 1.15 \\
\hline \multicolumn{7}{|l|}{ Level of maternal education } \\
\hline University & 64.9 & 1 & & 50.3 & 1 & \\
\hline Secondary & 65.8 & 1.01 & 0.86 to 1.19 & 47.3 & 0.93 & 0.74 to 1.17 \\
\hline Primary & 57.8 & 0.89 & 0.68 to 1.16 & 27.9 & 0.55 & 0.33 to 0.91 \\
\hline Missing responses & 63.5 & 0.97 & 0.81 to 1.17 & 45.7 & 0.90 & 0.67 to 1.22 \\
\hline \multicolumn{7}{|l|}{ Family's social class } \\
\hline Non-manual & 69.1 & 1 & & 50.7 & 1 & \\
\hline Manual & 58.4 & 0.86 & 0.73 to 1.02 & 37.0 & 0.72 & 0.56 to 0.94 \\
\hline Missing response & 54.5 & 0.81 & 0.58 to 1.12 & 33.3 & 0.65 & 0.34 to 1.27 \\
\hline \multicolumn{7}{|l|}{ FAS } \\
\hline High & 72.2 & 1 & & 50.9 & 1 & \\
\hline Middle & 60.4 & 0.83 & 0.72 to 0.96 & 46.4 & 0.91 & 0.73 to 1.12 \\
\hline Low & 56.9 & 0.78 & 0.62 to 0.99 & 38.2 & 0.75 & 0.53 to 1.05 \\
\hline \multicolumn{7}{|l|}{ Family structure } \\
\hline Two-parent family & 62.4 & 1 & & 51.0 & 1 & \\
\hline Mixed & 66.7 & 1.06 & 0.92 to 1.23 & 44.2 & 0.86 & 0.68 to 1.08 \\
\hline Single parent or other & 66.0 & 1.05 & 0.84 to 1.31 & 30.2 & 0.59 & 0.38 to 0.90 \\
\hline \multicolumn{7}{|l|}{ Chronic condition } \\
\hline No & 66.2 & 1 & & 48.5 & 1 & \\
\hline Yes & 52.3 & 0.78 & 0.61 to 1.00 & 27.1 & 0.55 & 0.34 to 0.89 \\
\hline
\end{tabular}

Data are prevalence $(\%)$ and bivariate association (PR and $95 \% \mathrm{Cl}$ ) according to independent variables.

FAS, family affluence scale; PR, prevalence ratio.

likely to have a very good PHS (PR 0.59; $95 \%$ CI 0.38 to 0.90 ) than those living with both father and mother.

Table 3 shows the generalised estimating equation models of PHS on socioeconomic position indicators, adjusted for age, family structure and chronic condition. Adjusted models showed no associations of primary level of maternal education (PR 0.62; 95\% CI 0.37 to 1.06 ) and less privileged family's social class (PR 0.78 ; $95 \%$ CI 0.61 to 1.02 ) with very good PHS in girls (table 3 ), although this association was observed in unadjusted models. However, it is important to mention that while the prevalence of very good PHS was $50.3 \%$ among those girls whose mothers had university studies, this prevalence was $37.3 \%$ in those whose mothers had primary or less level of education (table 2). In boys, adjusted models showed a statistically significant association between very good PHS and low FAS (PR 0.77; 95\% CI 0.61 to 0.99 ) (table 3).

\section{Overweight and obesity}

Prevalence of overweight and obesity was $11.4 \%$ in boys and $12.4 \%$ in girls (table 1 ).

Among boys and girls, a lower probability of being overweight or obese can be observed in the group of 15-16-year olds compared with the group aged 12-13 years, although no statistical significance was found (table 4). While the prevalence of overweight and obesity was $9.8 \%$ in boys and $5.6 \%$ in girls whose mothers were in the highest educational level, this prevalence was $17.1 \%$ and $27.3 \%$ among those boys and girls whose mothers were in the lowest educational level. In boys, overweight and obesity were associated with less privileged family's social class (PR 1.85; 95\% CI 1.03 to 3.34) (table 4); however, this association was lost in adjusted models (PR 1.75; 95\% CI 0.96 to 3.23 ) (table 5).

Table 5 shows that there were marked and statistically significant gradients in girls: other than family's social class, all indicators of less privileged socioeconomic position were associated with a higher probability of presenting overweight or obesity after adjusting for age and family structure.

\section{DISCUSSION}

The results of this study show that social inequalities in PHS and overweight or obesity were differently distributed among boys and girls. Among boys, socioeconomic differences were observed for PHS and overweight or obesity. Among girls, the most notable inequalities were observed for overweight or obesity, and no differences were found in PHS by socioeconomic indicators. Although some authors have suggested that adolescence is a period of equalisation in health, ${ }^{6}$ the present study has found social inequalities among some indicators of health during this period of life. 
Table 3 Six multivariate generalised estimating equation models (PR and $95 \% \mathrm{Cl}$ ) of very good perceived health status and pain on socioeconomic position indicators, among boys and girls of Barcelona, 2006

\begin{tabular}{|c|c|c|c|c|}
\hline & \multicolumn{4}{|c|}{ Very good perceived health } \\
\hline & \multicolumn{2}{|c|}{ Boys } & \multicolumn{2}{|l|}{ Girls } \\
\hline & $\overline{\mathbf{P R}}$ & $95 \% \mathrm{Cl}$ & $\overline{\mathbf{P R}}$ & $95 \% \mathrm{Cl}$ \\
\hline \multicolumn{5}{|c|}{ Level of paternal education } \\
\hline University & 1 & & 1 & \\
\hline Secondary & 0.87 & 0.74 to 1.03 & 0.93 & 0.73 to 1.17 \\
\hline Primary & 0.75 & 0.55 to 1.01 & 0.72 & 0.48 to 1.09 \\
\hline Missing responses & 0.74 & 0.60 to 0.91 & 0.85 & 0.64 to 1.15 \\
\hline \multicolumn{5}{|c|}{ Level of maternal education } \\
\hline University & 1 & & 1 & \\
\hline Secondary & 1.08 & 0.92 to 1.28 & 1.00 & 0.80 to 1.24 \\
\hline Primary & 0.96 & 0.73 to 1.26 & 0.62 & 0.37 to 1.06 \\
\hline Missing responses & 1.01 & 0.84 to 1.22 & 0.85 & 0.62 to 1.15 \\
\hline \multicolumn{5}{|l|}{ Family's social class } \\
\hline Non-manual & 1 & & 1 & \\
\hline Manual & 0.86 & 0.73 to 1.03 & 0.78 & 0.61 to 1.02 \\
\hline Missing response & 0.80 & 0.57 to 1.12 & 0.71 & 0.31 to 1.61 \\
\hline \multicolumn{5}{|l|}{ FAS } \\
\hline High & 1 & & 1 & \\
\hline Middle & 0.82 & 0.71 to 0.95 & 0.95 & 0.77 to 1.17 \\
\hline Low & 0.77 & 0.61 to 0.99 & 0.83 & 0.58 to 1.16 \\
\hline
\end{tabular}

Independent models were calculated for each socioeconomic position indicator

Models were controlled by school and adjusted for age, family structure and chronic condition.

FAS, family affluence scale; PR, prevalence ratio.

For PHS, the expected gradient was found such that less privileged family socioeconomic position was associated with a lower probability of having a very good PHS in boys. Among girls, however, this association disappeared after controlling for confounding factors such as age, family structure and chronic condition. This finding fits with a study carried out by Starfield et al where adolescents of the highest socioeconomic position were more likely to be in the best health profiles (according to satisfaction, discomfort, risks and resilience). ${ }^{29}$ It is important to mention, however, that most studies that have analysed social inequalities in perceived health among adolescent population have used the poor PHS as an indicator. However, in the current study, very good PHS was used, as we believe that indicators of good health are necessary in the study of social inequalities among young people due to their low morbidity. Nevertheless, while some studies found associations between PHS and socioeconomic position among adolescents (teenagers from low socioeconomic position were more likely to present poor PHS), other studies have found no association.

Furthermore, we found that boys were more likely to report very good PHS than girls, which is consistent with the findings of the Health Behaviour in School-Aged Children study ${ }^{26}$ carried out in Europe and also with those Goodman et al ${ }^{30}$ in the USA. These results could be explained by another study that suggested that girls are more likely to self-report general ill health and physical symptoms as well as psychological distress. ${ }^{31}$ Another study, carried out by Sweeting et al ${ }^{32}$, found that sex differences in self-image contributed to excess in psychosomatic symptoms and depressive mood in girls.

Overweight and obesity were also associated with less privileged socioeconomic position in girls, with levels two or three times higher than in the most privileged socioeconomic group. This finding is consistent with other studies carried out in Spain ${ }^{33}$ and also in the USA. ${ }^{34}$ Previous studies have found a strongest association between socioeconomic indicators and obesity among
Table 4 Overweight and obesity among boys and girls of Barcelona, 2006

\begin{tabular}{|c|c|c|c|c|c|c|}
\hline & \multicolumn{6}{|c|}{ Overweight and obesity } \\
\hline & \multicolumn{3}{|l|}{ Boys } & \multicolumn{3}{|l|}{ Girls } \\
\hline & $\begin{array}{l}\text { Prevalence } \\
(\%)\end{array}$ & PR & $95 \% \mathrm{Cl}$ & $\begin{array}{l}\text { Prevalence } \\
(\%)\end{array}$ & PR & $95 \% \mathrm{Cl}$ \\
\hline \multicolumn{7}{|l|}{ Age, years } \\
\hline $12-13$ & 9.8 & 1 & & 10.1 & 1 & \\
\hline 14 & 12.7 & 1.08 & 0.54 to 2.18 & 12.3 & 0.83 & 0.56 to 2.61 \\
\hline $15-16$ & 11.7 & 0.83 & 0.43 to 1.62 & 14.7 & 0.68 & 0.36 to 1.31 \\
\hline \multicolumn{7}{|l|}{ Type of school } \\
\hline $\begin{array}{l}\text { Private/ } \\
\text { subsidized }\end{array}$ & 10.8 & 1 & & 10.4 & 1 & \\
\hline Public & 12.1 & 1.11 & 0.61 to 2.02 & 16.8 & 1.62 & 0.92 to 2.84 \\
\hline \multicolumn{7}{|c|}{ Level of paternal education } \\
\hline University & 11.3 & 1 & & 3.9 & 1 & \\
\hline Secondary & 11.2 & 0.99 & 0.50 to 2.94 & 15.6 & 3.98 & 1.60 to 9.91 \\
\hline Primary & 11.1 & 0.98 & 0.35 to 3.70 & 28.2 & 7.19 & $\begin{array}{l}2.83 \text { to } \\
18.23\end{array}$ \\
\hline $\begin{array}{l}\text { Missing } \\
\text { responses }\end{array}$ & 11.0 & 0.96 & 0.44 to 2.10 & 18.3 & 4.67 & $\begin{array}{l}1.81 \text { to } \\
12.07\end{array}$ \\
\hline \multicolumn{7}{|c|}{ Level of maternal education } \\
\hline University & 9.8 & 1 & & 5.6 & 1 & \\
\hline Secondary & 12.8 & 1.31 & 0.67 to 2.55 & 13.8 & 2.48 & 1.10 to 5.59 \\
\hline Primary & 17.1 & 1.75 & 0.74 to 4.13 & 27.3 & 4.90 & $\begin{array}{l}2.04 \text { to } \\
11.76\end{array}$ \\
\hline $\begin{array}{l}\text { Missing } \\
\text { responses }\end{array}$ & 9.3 & 0.95 & 0.41 to 2.20 & 18.2 & 3.27 & 1.36 to 7.86 \\
\hline \multicolumn{7}{|c|}{ Family's social class } \\
\hline Non-manuals & 8.9 & 1 & & 8.3 & 1 & \\
\hline Manuals & 16.5 & 1.85 & 1.03 to 3.34 & 20.0 & 2.4 & 1.35 to 4.32 \\
\hline $\begin{array}{l}\text { Missing } \\
\text { responses }\end{array}$ & 18.2 & 2.04 & 0.77 to 5.36 & 36.4 & 4.4 & $\begin{array}{l}1.81 \text { to } \\
10.68\end{array}$ \\
\hline \multicolumn{7}{|l|}{ FAS } \\
\hline High & 12.6 & 1 & & 9.0 & 1 & \\
\hline Middle & 6.5 & 0.51 & 0.24 to 1.04 & 11.2 & 1.23 & 0.61 to 2.47 \\
\hline Low & 20.8 & 1.64 & 0.85 to 3.16 & 25.5 & 2.82 & 1.38 to 5.77 \\
\hline \multicolumn{7}{|c|}{ Family structure } \\
\hline $\begin{array}{l}\text { Two-parent } \\
\text { family }\end{array}$ & 11.0 & 1 & & 11.3 & 1 & \\
\hline Mixed & 10.4 & 0.94 & 0.50 to 1.77 & 15.1 & 1.33 & 0.73 to 2.41 \\
\hline $\begin{array}{l}\text { Single parent } \\
\text { or other }\end{array}$ & 14.6 & 1.32 & 0.58 to 3.03 & 10.3 & 0.90 & 0.33 to 2.47 \\
\hline \multicolumn{7}{|c|}{ Chronic condition } \\
\hline No & 12.1 & 1 & & 12.2 & 1 & \\
\hline Yes & 5.9 & 0.48 & 0.15 to 1.50 & 15.5 & 1.25 & 0.56 to 2.79 \\
\hline
\end{tabular}

Data are prevalence and bivariate association (PR and $95 \% \mathrm{Cl}$ ) according to independent variables.

FAS, family affluence scale; PR, prevalence ratio.

girls than boys. ${ }^{16} 3536$ In our study, there were marked and statistically significant gradients in girls, all indicators of less privileged socioeconomic position being associated with a higher probability of presenting overweight or obesity. One review suggests that there are gender differences in exposure and vulnerability to obesogenic environments, which could explain differences between boys and girls found in the present study. ${ }^{27}$ De Spiegelaere et $a l^{36}$ suggested that this different relationship in boys and girls could be due to the most precocious pubertal development in girls. Moreover, some studies have found that low socioeconomic position is associated with less physical activity and less access to healthy foods and sedentary behaviour, ${ }^{37}$ and this could have a different impact by gender.

It is possible that differences between results found in studies of different social inequalities among adolescents could be explained by the indicator of socioeconomic position or health used in each study. In a study carried out in seven European 
Table 5 Six multivariate generalised estimating equation models (PR and $95 \% \mathrm{Cl}$ ) of overweight and obesity on socioeconomic position indicators, among boys and girls of Barcelona, 2006

\begin{tabular}{|c|c|c|c|c|}
\hline & \multicolumn{4}{|c|}{ Overweight and obesity } \\
\hline & \multicolumn{2}{|c|}{ Boys } & \multicolumn{2}{|l|}{ Girls } \\
\hline & $\overline{\mathbf{P R}}$ & $95 \% \mathrm{Cl}$ & $\overline{\mathbf{P R}}$ & $95 \% \mathrm{CI}$ \\
\hline \multicolumn{5}{|c|}{ Level of paternal education } \\
\hline University & 1 & & 1 & \\
\hline Secondary & 0.87 & 0.44 to 1.71 & 2.74 & 1.12 to 6.67 \\
\hline Primary & 0.82 & 0.28 to 2.36 & 5.05 & 1.90 to 13.43 \\
\hline Missing responses & 0.72 & 0.32 to 1.64 & 3.02 & 1.18 to 7.72 \\
\hline \multicolumn{5}{|c|}{ Level of maternal education } \\
\hline University & 1 & & 1 & \\
\hline Secondary & 1.24 & 0.63 to 2.44 & 1.66 & 0.78 to 3.55 \\
\hline Primary & 1.49 & 0.60 to 3.68 & 3.30 & 1.34 to 8.14 \\
\hline Missing responses & 0.81 & 0.34 to 1.91 & 2.14 & 0.94 to 4.85 \\
\hline \multicolumn{5}{|l|}{ Family's social class } \\
\hline Non-manuals & 1 & & 1 & \\
\hline Manuals & 1.76 & 0.96 to 3.23 & 1.64 & 0.87 to 3.08 \\
\hline Missing responses & 1.83 & 0.67 to 5.01 & 4.39 & 1.73 to 11.07 \\
\hline \multicolumn{5}{|l|}{ FAS } \\
\hline High & 1 & & 1 & \\
\hline Middle & 0.52 & 0.25 to 1.08 & 1.03 & 0.54 to 1.95 \\
\hline Low & 1.71 & 0.86 to 3.38 & 2.41 & 1.13 to 5.11 \\
\hline
\end{tabular}

Independent models were calculated for each socioeconomic position indicator Models were controlled by school and adjusted by age and family structure.

FAS, family affluence scale; PR, prevalence ratio.

countries, while educational level of parents explained inequalities in health-related quality of life among children, FAS was the socioeconomic indicator that best explained inequalities in health-related quality-of-life indicators in the adolescent population. ${ }^{38}$ A recent study carried out in the city of Barcelona did not find any differences in satisfaction with health or welfare according to social class or educational level of parents; however, differences in resilience (which covers family involvement, social problem-solving, physical activity and home safety and health) were found in both socioeconomic indicators. ${ }^{39}$

Due to the lack of consensus on which socioeconomic indicators should be used in the study of social inequalities in health among adolescents, parental occupational status and educational level were used in the present study. Despite this fact, several studies have suggested that adolescents are able to provide valid information about their parents' socioeconomic position. ${ }^{40}$ Pueyo et $a l^{39}$ found that paternal occupation followed by maternal educational level were the most valid indicators of socioeconomic position in the adolescent population, although there was a significant problem with the number of non-responses. Consequently, it is possible that some of the social class categories were over-represented or under-represented. To solve the problem of a possible selection bias, this study used the family's social class and the FAS, the latter having been developed to apply in children and adolescents by Currie et al, as a complementary socioeconomic indicator. Currie et al ${ }^{41}$ found that while $98 \%$ of 11-15-year olds were able to answer on car ownership, whether or not they shared a bedroom, and telephones in the home, only $78 \%$ could provide codeable data for father's social class, which was similar to the results found in the present study. Furthermore, FAS has been validated in many European countries, including Spain, and also used as a predictor of socioeconomic position in previous studies of young people's health. ${ }^{26}$

\section{Strengths and limitations}

First, in almost all schools, the response ratio was above $80 \%$; thus, we did not expect to have a selection bias in the final sample of this study due to non-response. However, in two schools, the population of which was from the medium and low socioeconomic levels, the response ratio was approximately $50 \%$. Therefore, the percentage of individuals in the lower socioeconomic level would be higher, and as a result the association found would be underestimated.

The main strength of the present study is that it specifically focused on adolescence and explored different measurements of socioeconomic status. The fact of finding social inequalities in health, even in this stage of life, highlights the need for interventions aimed to diminish them in every period of life.

This study has some limitations that should be mentioned. First, self-reported weight and height were used to determine overweight and obesity, and as is already known, there is a problem with the validity and reliability of these data among adolescents (boys over-report their height, girls under-report their weight, with the consequent result of underestimation of overweight and obesity ${ }^{42}$ ). This probably happened in our study, but this would not affect the study of social inequalities, except if under-reporting were differential depending on parents' social class, something that, to our knowledge, has not been studied in Spain.

Second, the lack of information about subjects' physical activity, dietary habits and nationality was a limitation in this study. Previous studies have shown that physical activity, dietary habits and ethnicity were associated with the prevalence of overweight and obesity, and also other health indicators, among adolescents. ${ }^{43} 44$ However, some studies have suggested that physical activity and dietary habits in young people are associated with parent's social class and family structure-both variables were used in this study. ${ }^{45}$ Moreover, due to the significant increase of immigration in Europe in recent years and its impact on adolescents' health, ${ }^{46}$ information of nationality should be elicited in future studies of social inequalities in health among young people.

Third, the use of cross-sectional data did not allow us to evaluate causal inference of socioeconomic factors on adolescents' health, nor the temporal relation between exposure and outcome. Reported adolescents' PHS was probably established as a consequence of earlier parents' occupation. Furthermore,

\section{What is already known on this subject}

- Adolescence has a vital importance in the adoption of healthy or risky lifestyles, which probably determine individuals health in adult life.

- Some studies have suggested weak or no association between socioeconomic status and health of young people, whereas others have found a strong association.

\section{What this study adds}

There are social inequalities in perceived health status and overweight or obesity among adolescents.

- Social inequalities in health are distributed differently among boys and girls.

- The adolescent population should be included in all policies and interventions aimed to reduce social inequalities in health. 
longitudinal studies have shown that social inequalities in health among adolescents have long-term effects, affecting health in adulthood. Children and adolescents who grow up in unfavourable socioeconomic circumstances are more likely to present unhealthy behaviour, higher morbidity and mortality. ${ }^{9} 47$

Finally, the sample size calculated to estimate the pain prevalence (based in a 15\%) has more variance and is more efficient to estimate overweight or obesity prevalence (10\% approximately). Instead, this sample size could be insufficient to estimate very good PHS prevalence (55\% approximately), so power could be not enough to find significant differences.

\section{Conclusions and recommendations}

This study has shown that there are social inequalities among adolescents, whereby those from a less privileged socioeconomic position have a higher probability of presenting worse health indicators and a lower probability of reporting very good PHS. Therefore, future studies and surveillance of social inequalities in health among the adolescent population are needed, as the decrease of inequalities among this collective would improve their health-related quality of life and probably reduce future public health costs due to its association with social and health problems in adulthood. ${ }^{89} 48$ Moreover, gender differences in the impact of socioeconomic variables in health need to be considered in epidemiological and intervention studies. Finally, our findings stress the importance of including the adolescent population in the policy agenda of health inequalities and of increasing efforts to reduce social inequalities in health in every period of human lives.

Acknowledgements The authors gratefully acknowledge funding support from the Fondo de Investigación Sanitaria-Instituto de Salud Carlos III (PI040728); Sociedad para el Estudio de las Enfermedades del Raquis-Beca de Investigación GEER 2006; Direction de l'Instruction Publique, de la Culture et du Sport, Fribourg and Direction de la Santé et des affaires Sociales, Fribourg. The authors' work was independent of the funding institutions.

Competing interests None.

Patient consent Obtained

Ethics approval This study was conducted with the approval of the ethics committee of the Vall d'Hebrón Hospital.

Provenance and peer review Not commissioned; externally peer reviewed.

\section{REFERENCES}

1. Barbosa J, Barros MB. Epidemiología e desigualdade: notas sobre a teoria e a história. Rev Panam Salud Pública 2002;12:375-83.

2. Marmot M. Commission on Social Determinants of Health. Achieving health equity: from root causes to fair outcomes. Lancet 2007;370:1153-63.

3. Black D, Morris JN, Smith C et al. Black Report. Inequalities in health: report of a research working group. London: Department of Health and Social Security, 1980.

4. Currie C, Gabhainn SN, Godeau E, et al, eds. Inequalities in young people's health: international report from the HBSC 2006/06 survey. WHO Policy Series: Health policy for children and adolescents Issue 5, WHO Regional Office for Europe. Copenhagen, 2008.

5. Morlachetti A. Reunión de Expertos sobre Población, Desigualdades y Derechos Humanos. CELADE- Deivisión de Población CEPAL, Naciones Unidas. Políticas de salud sexual y reproductiva para adolescentes y jóvenes. un enfoque desde los derechos humanos, Santiago de Chile, 2006. http://www. cepal.cl/publicaciones/xml/1/32261/lcg2346-P 4.pdf (accessed 02 Jun 2008)

6. West $\mathbf{P}$. Health inequalities in the early years: is there equalisation in youth? Soc Sci Med 1997; 44:833-58.

7. Due $\mathbf{P}$, Lynch J, Holstein B, et al. Socioeconomic health inequalities among a nationally representative sample of Danish adolescents: the role of different types of social relations. J Epidemiol Community Health 2003;57:692-8.

8. Van de Mheen H, Stronks K, Looman CWN, et al. Does childhood socio-economic status influence adult health through behavioural factors? Int J Epidemiol 1998;27:431-7.

9. Bosma H, Van de Mheen H, Machkenback JP. Social class in childhood and general health in adulthood: questionnaire study of contribution of psychological attributes. BMJ 1999;318:18-22
10. Wang Y, Lobstein T. Worldwide trends in childhood overweight and obesity. Int $J$ Pediatr Obes 2006;1:11-25.

11. World Health Organization. Prevalence of excess body weight and obesity in children and adolescents. Geneva, Switzerland: European Environment and Health Information System, 2007, Fact Sheet No. 2.3

12. Sobal J, Stunkard AJ. Socioeconomic status and obesity: a review of the literature Psychol Bull 1989;105:260-75

13. Ball K, Crawford D. Socioeconomic status and weight change in adults: a review. Soc Sci Med 2005:60:1987-2010.

14. De Spiegelaere M, Dramaix M, Hennart P. The influence of socioeconomic status on the incidence and evolution of obesity during early adolescence. Int $\mathrm{J}$ Obes 1998;22:268-74.

15. Gnavi R, Spagnoli TD, Galotto C, et al. Socioeconomic status, overweight and obesity in prepuberal children: a study in an area of Northern Italy. Eur J Epidemiol 2000:16:797-803.

16. Klein-Platat C, Wagner A, Haan MC, et al. Prevalence and sociodemographic determinants of overweight in young French adolescents. Diabetes Metab Res Rev 2003;19:153-8.

17. Kautiainen S, Koivisto AM, Koivusilta L, et al. Sociodemographic factors and a secular trend of adolescents overweight in Finland. Int J Pediatr Obes 2009;23:1-11.

18. Melnick TA, Rhoades SJ, Wales KR, et al. Overweight school children in New York City: prevalence estimates and characteristics. Int J Obes 1998:22:7-13.

19. IIder EL, Benyamani Y. Self-rated health and mortality: a review of twenty-seven community studies. J Health Soc Behav 1997;38:21-37.

20. Burstroem B, Fredlund P. Self-rated health: is it a good predictor of subsequent mortality among adults in lower as well as in higher social classes? Community Health 2001:55:836-40

21. Pellisé F, Balagué $F$, Rajmil L, et al. Prevalence of low back pain and its effect on health-related quality of life in adolescents. Arch Pediatr Adolesc Med 2009;163:65-71.

22. Ventura A, Cárcel C. Index de capacitat econòmica familiar a la ciutat de Barcelona II. Barcelona: Ajuntament de Barcelona. Gabinet tècnic de programació, 1999.

23. Sobradillo B, Aguirre A, Aresti U, et al. Curvas y tablas de crecimiento. Estudios longitudinal y tranversal. Fundación F. Orbegozo. In: ERGON, ed. Patrones de crecimiento y desarrollo en España. Madrid: Atlas de gráficas y tablas, 2004:145-68.

24. Moreno L, Sarriá A, Fleta J, et al. Trends in body mass index and overweight among children and adolescents in the region of Aragon (Spain) from 1985 to 1995. Int J Obes Metab Disord 2000;24:925-31. In: Riaño Galaño I. Simposio I. Avances en e manejo del sobrepeso y de la obesidad. Sobrepeso y obesidad en la adolescencia. Nuestra realidad. Bol Pediatr 2007;47:8-12.

25. Grupo de Trabajo de la Sociedad Española de Epidemiología. La medición de la clase social en ciencias de la salud. Barcelona: SG Editores, 1995.

26. Currie C, et al, eds. Young People's Health in Context: international report from the HBSC 2001/02 survey. WHO Policy Series: Health policy for children and adolescents Issue 4. Copenhagen: WHO Regional Office for Europe, 2004.

27. Sweeting H. Gender dimensions of obesity in childhood and adolescence. Nutr J 2008; 7:1-14.

28. Schiaffino A, Rodríguez $\mathrm{M}$, Pasarín Ml, et al. Odds ratio or prevalence ratio? Their use in cross-sectional studies. Gac Sanit 2003;17:70-4.

29. Starfield B, Riley AW, Witt WP, et al. Social class gradients in health during adolescence. J Epidemiol Community Health 2002;56:354-61.

30. Goodman E. The role of socioeconomic status gradients in explaining differences in US adolescents' health. Am J Public Health 1999:89:1522-8.

31. Sweeting H, West P. Sex differences in health at ages 11, 13 and 15. Soc Sci Med 2003; $56: 31-9$

32. Sweeting HN, West PB, Der GJ. Explanations for female excess psychosomatic symptoms in adolescence: evidence from a school-based cohort in the West of Scotland. BMC Public Health 2007; 7:298.

33. Moreno LA, Tomás C, González-Gross M, et al. Micro-environmental and socio-demographic determinants of childhood obesity. Int J Obes 2004;28:S16-S20.

34. Wang $\mathbf{Y}$, Zhang 0 . Are American children and adolescents of low socioeconomic status at increased risk of obesity? Changes in the association between overweight and family income between 1971 and 2002. Am J Clin Nutr 2006;84:707-16.

35. Lien N, Kumar BN, Holmboe-Ottesen G, et al. Assessing social differences in overweight among 15- to 16 -year-old ethnic Norwegians from Oslo by register data and adolescent self-reported measures of socio-economic status. Int J Obes (Lond) 2007; 31:30-8

36. De Spiegelaere M, Dramaix M, Hennart P. Social class and obesity in 12-year-old children in Brussels: influence of gender and ethnic origin. Eur $\mathrm{J}$ Pediat 1998; 157:432-5

37. Lioret S, Maire B, Volatier JL, et al. Child overweight in France and its relationship with physical activity, sedentary behaviour and socioeconomic status. Eur J Clin Nutr 2007;61:509-16

38. von Rueden U, Gosch A, Rajmil L, et al. Socioeconomic determinants of health related quality of life in childhood and adolescence: results from a European study. $J$ Epidemiol Community Health 2006;60:130-5.

39. Pueyo MJ, Serra-Sutton V, Alonso J, et al. Self-reported social class in adolescents: validity and relationship with gradients in self-reported health. BMC Health Serv Res 2007; 7:151. 
40. Lien N, Friestad C, Klepp KI. Adolescent's proxy reports of parents' socioeconomic status: how valid are they? J Epidemiol Community Health 2001;55:731-7.

41. Currie CE, Elton RA, Todd J, et al. Indicators of socioeconomic status for adolescents: the WHO health behavior in school-aged children survey. Health Educ Res 1997;12:385-97.

42. Galán I, Gandarillas A, Febrel C, et al. Validación del peso y la talla autodeclarados en población adolescente. Gac Sanit 2001;15:490-7.

43. Haas JS, Lee LB, Kaplan CP, et al. The association of race, socioeconomic status, and health insurance status with the prevalence of overweight among children and adolescents. Am J Public Health 2003;93:2105-10.

44. Aranceta J, Pérez C, Ribas L, et al. Epidemiología y factores determinantes de la obesidad infantil y juvenil en España. Rev Pediatr Aten Primaria 2005; 7(Suppl 1):S13-20.
45. Roos EB, Hirvonen T, Mikkilä V, et al. Household educational level as a determinant of consumption of raw vegetables among male and female adolescents. Prev Med 2001;33:282-91.

46. Saxena S, Eliahoo J, Majeed A. Socioeconomic and ethnic group differences in self reported health status and use of health services by children and young people in England: cross sectional study. BMJ 2002;325:520.

47. Power C, Hyppönen E, Smith GD. Socioeconomic position in childhood and early adult life and risk of mortality: a prospective study of the mothers of the 1958 British birth cohort. Am J Public Health 2005;95:1396-402.

48. Gortmaker SL, Must A, Perrin JM, et al. Social and economic consequences of overweight in adolescence and young adulthood. N Engl J Med 1993;329:1008-12 